\title{
Genetic Diversity of Walnut Revealed by AFLP and RAPD Markers
}

\author{
Zheng $\mathrm{Xu}^{1}$, Tingxing $\mathrm{Hu}^{1}$ \& Fan Zhang ${ }^{1}$ \\ ${ }^{1}$ College of Forestry, Sichuan Agricultural University, Ya'an 625014, China \\ Correspondence: Tingxing Hu, College of Forestry, Sichuan Agricultural University, Ya'an 625014, China. Tel: \\ 86-835-288-2132. E-mail: hutx001@yahoo.com.cn
}

$\begin{array}{lc}\text { Received: February 16, } 2012 & \text { Accepted: March 5, } 2012 \quad \text { Online Published: June 19, } 2012 \\ \text { doi:10.5539/jas.v4n7p271 } & \text { URL: http://dx.doi.org/10.5539/jas.v4n7p271 }\end{array}$

The research was supported by the National Key Technology R\&D Program of China (No. 2006BAC01A11).

\begin{abstract}
AFLP and RAPD methods were used to investigate the genetic diversity of walnuts in western Sichuan plateau and Qinba mountainous regions. 35 samples were collected from 8 different regions, and 32 RAPD primers and 28 AFLP primer combinations were identified with polymorphism bands among the entire. 324 and 2155 fragments were respectively produced by RAPD and AFLP makers, and $86.1 \%$ of RAPD bands and $57.2 \%$ of AFLP bands showed polymorphic with the size of 180 2000 bp and 50 1800 bp, respectively. The average amplified were 10.1 fragments per primer by RAPD and 76.9 fragments per pair primer by AFLP. The more polymorphic for genetic resource in Western Sichuan Plateau was observed by both RAPD and AFLP. The high number of alleles and the high expected genetic diversity detected with RAPD and AFLP markers indicate that western China has an important genetic diversity pool and abundant genetic variance of walnuts.
\end{abstract}

Keywords: Juglans regia L, AFLP, RAPD, genetic diversity

\section{Introduction}

Walnut (Juglans regia $\mathrm{L}$ ), rich in nutritious substances and various microelement, is one of important economic species in the world (Martínez et al., 2010). Because of its breeding characteristics, walnut has formed abundant genetic diversities through a long term evolution under complicated environment (Wu et al., 2000a; Yang, 2005). However, little has been known of the evolution connections among walnut seeds and the phylogenetic relationships among the varieties. The early research methods were main morphological and agronomical traits, biochemical markers such as cell karyotype analysis and isoenzymes (Fornari et al., 2001; Malvolti et al., 2001), these methods are sensitive to environmental factors and the number of markers is limited, thus the research of walnut diversity has limited.

The information on structure, organization, and evolution of genomes has been greatly improved by the molecular marker techniques such as RFLP, ISSR, RAPD, and AFLP (Cervera et al., 2000; Niu et al., 2007; Li et al., 2011). In comparison with other marker types, these DNA-based markers techniques can detect the genetic diversity of specie in all tissues at all stages of development without affecting by environmental condition (Di et al., 2006). Moreover, the genetic diversity within or among species can also been analysed following these molecular marker techniques (Cervera et al., 2000; Qi et al., 2011). As a result of it, the development of molecular marker technique distinctly increases the study of plant genetic diversity (Soriano et al., 2005).

China is regard as a great center for origin and genetic variation of walnut (Jia \& Xu, 2006). The aim of paper was to perform variety identification of the walnuts by RAPD and AFLP makers in different environment in western China. Both of them provided a reliable and facility way to identify and characterize walnut varieties cultivated in China and to determine the genetic relationship among the populations for using, exploring and protecting the germ plasma resources of walnut in China.

\section{Materials and Methods}

\subsection{Plant Material}

Thirty-five superior walnuts were collected at the detachable time in the two different climate regions, including BaTang, XiangCheng, JiuLong, and DeRong County in Western Sichuan plateau as well as NanJiang, TongJiang, and WanYuan County in Qinba mountainous regions (Table 1). All the seeds rise in the conservatory of Sichuan 
Agricultural University.

Table 1. The walnuts accessions evaluated in this study and their origin

\begin{tabular}{lccccc}
\hline Number & Locality & Number & Locality & Number & Locality \\
\hline BT-1 & Batang & JL-3 & Jiulong & NJ-5 & Nanjiang \\
BT-2 & Batang & JL-4 & Jiulong & TJ-1 & Tongjiang \\
BT-3 & Batang & JL-5 & Jiulong & TJ-2 & Tongjiang \\
BT-4 & Batang & DR-1 & Derong & TJ-3 & Tongjiang \\
BT-5 & Batang & DR-2 & Derong & TJ-4 & Tongjiang \\
XC-1 & Xiangcheng & DR-3 & Derong & TJ-5 & Tongjiang \\
XC-2 & Xiangcheng & DR-4 & Derong & WY-1 & Wanyuan \\
XC-3 & Xiangcheng & DR-5 & Derong & WY-2 & Wanyuan \\
XC-4 & Xiangcheng & NJ-1 & Nanjiang & WY-3 & Wanyuan \\
XC-5 & Xiangcheng & NJ-2 & Nanjiang & WY-4 & Wanyuan \\
JL-1 & Jiulong & NJ-3 & Nanjiang & WY-5 & Wanyuan \\
JL-2 & Jiulong & NJ-4 & Nanjiang & & \\
\hline
\end{tabular}

DNA was extracted from fresh leaves of each accession using the method of Chen \& Wang (2004) and Zhang et al (2003). DNA concentration and quality were detected by Ultrospec 2100 ultraviolet scanner. The extracted DNA was stored at $-20^{\circ} \mathrm{C}$.

\subsection{RAPD Analysis}

The total volume of PCR amplification reaction system was $20 \mu \mathrm{L}$, which contained $40 \eta$ g genomic DNA, 2.0 $\mathrm{mM} \mathrm{MgCl} 2,2 \mu \mathrm{L} 10 \times$ PCR Buffer, $25 \mu \mathrm{M}$ dNTP, $1.0 \mathrm{U}$ Taq DNA polymerase, and $0.4 \mu \mathrm{M}$ random primer. PCR amplification were performed in programmed $5 \mathrm{~min}$ at $94{ }^{\circ} \mathrm{C}$ followed by 40 cycles of $1 \mathrm{~min}$ at $94{ }^{\circ} \mathrm{C}, 1 \mathrm{~min}$ at $36{ }^{\circ} \mathrm{C}, 1 \mathrm{~min} 30 \mathrm{~s}$ at $72{ }^{\circ} \mathrm{C}$, and $10 \mathrm{~min}$ at $72{ }^{\circ} \mathrm{C}$. The amplified products were separated by $1.5 \%$ agarose gel electrophoresis, and stained by EB, and taken pictures (Di et al., 2006).

\subsection{AFLP Analysis}

Genomic DNA was restricted with two restriction endonucleases: EcoRI and MseI, and double-stranded adaptors were ligated to the ends of DNA fragments, generating template DNA for subsequent PCR amplifications (preselectice followed by selective). Approximately $200 \mathrm{ng}$ of DNA was digested with EcoRI and MseI enzymes combinations (Zhao et al., 2006). The AFLP analysis followed the method describing by Vos et al. (1995) with some modifications. Preamplification was done on PTC- 100 thermal cycle using 25 cycles of $30 \mathrm{~s}$ at $94{ }^{\circ} \mathrm{C}$ followed $1 \mathrm{~min}$ at $56{ }^{\circ} \mathrm{C}, 1 \mathrm{~min}$ at $72{ }^{\circ} \mathrm{C}$, and $10 \mathrm{~min}$ at $72{ }^{\circ} \mathrm{C}$. The selective amplification were composed of 13 cycles of $30 \mathrm{~s}$ at $94{ }^{\circ} \mathrm{C}, 30 \mathrm{~s}$ at $65^{\circ} \mathrm{C}$, and $1 \mathrm{~min}$ at $72^{\circ} \mathrm{C}$, and the other amplification were 13 cycles of $30 \mathrm{~s}$ at $94{ }^{\circ} \mathrm{C}, 30 \mathrm{~s}$ at $56{ }^{\circ} \mathrm{C}$, and $1 \mathrm{~min}$ at $72{ }^{\circ} \mathrm{C}$. PCR products were separated on $5 \% \mathrm{w} / \mathrm{v}$ denaturing polyacrylamide gels and were visualized after silver staining (Zhao et al., 2006; Lu et al., 2001).

\subsection{Statistical Analyses}

All distinctively and unambiguously polymorphic bands were scored ( 1 for present and 0 for absent), and then the original data were input to computer to get the gene diversity and Genetic Distance $(G D)$. The similarity coefficient was calculated to get the similarity coefficient matrix, and the cluster analysis was carried out with the sequential agglomerative hierarchical nested cluster analysis program (SAHN) and un-weighted pair group method analysis (UPGMA) in NTSYSpc 2.10e software. The cluster result of the AFLP and RAPD primer combined was used to perform Mantel test to be compared with the cluster result of AFLP or RAPD primer individually.

\section{Results}

\subsection{RAPD and AFLP Analysis}

32 pairs of RAPD primer which amplified clear bands and had abundant polymorphism were selected from 330 pairs of primer. The selected primers were used to analyze 35 walnuts and amplified 324 bands in total. The amplified bands ranged from 180 to $2000 \mathrm{bp}$. In these bands, there were 279 polymorphic bands and the 
percentage of polymorphic loci arrived at $86.1 \%$.On an average, 10.1 bands were amplified per primer. Figure 1 shows an example of RAPD banding profile with primer O-6.

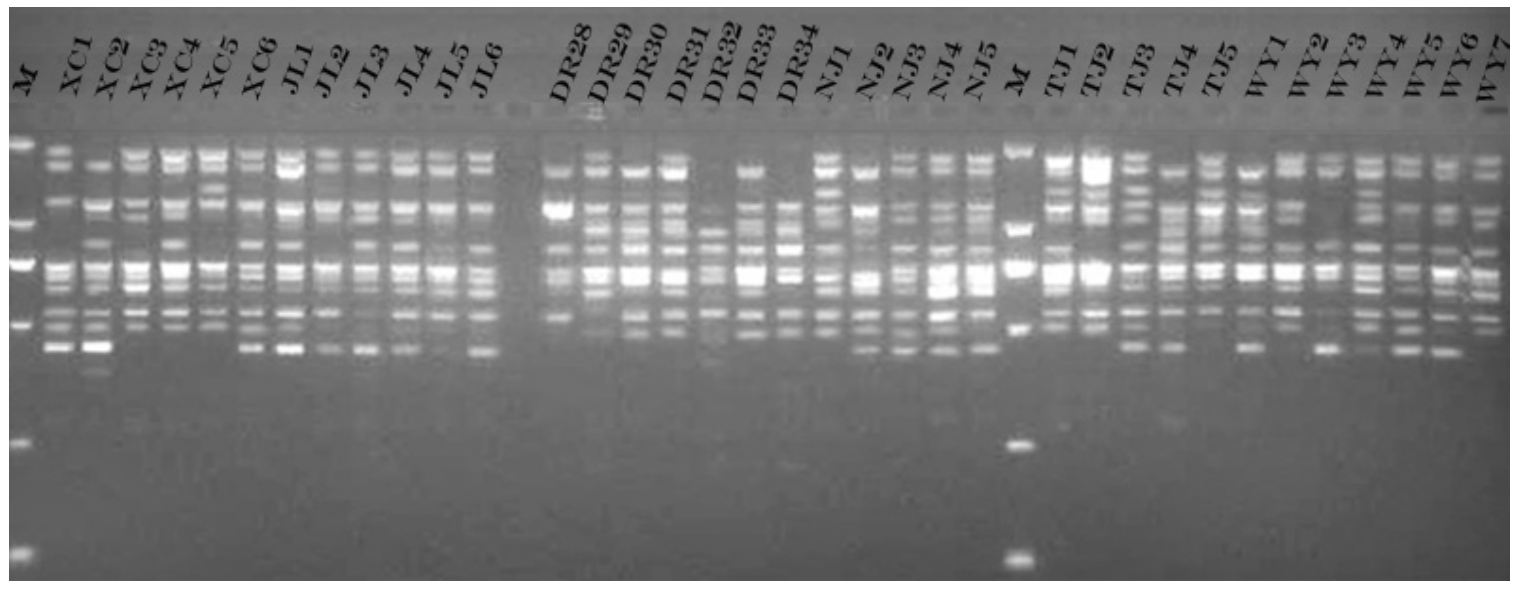

Figure 1. RAPD patterns amplified with the primer O-6

48 AFLP primer combinations (Eco I +3 and Mse I +3 primers) were used to detect the polymorphism among walnuts samples, and 28 primer combinations were polymorphic. 2155 polymorphic AFLP loci were to screen the same 35 genotypes of walnuts, and the polymorphic bands ranged from 50 to $1800 \mathrm{bp}$. The polymorphism rate was about $57.2 \%$, and the bands amplified by a pair of primer combination were 76.9 in average. Genetic polymorphism was rich among the 35 domestic walnut genotypes by AFLP. An example of banding profiles with E-AAG/M-CCC primer combination is given in Figure 2.

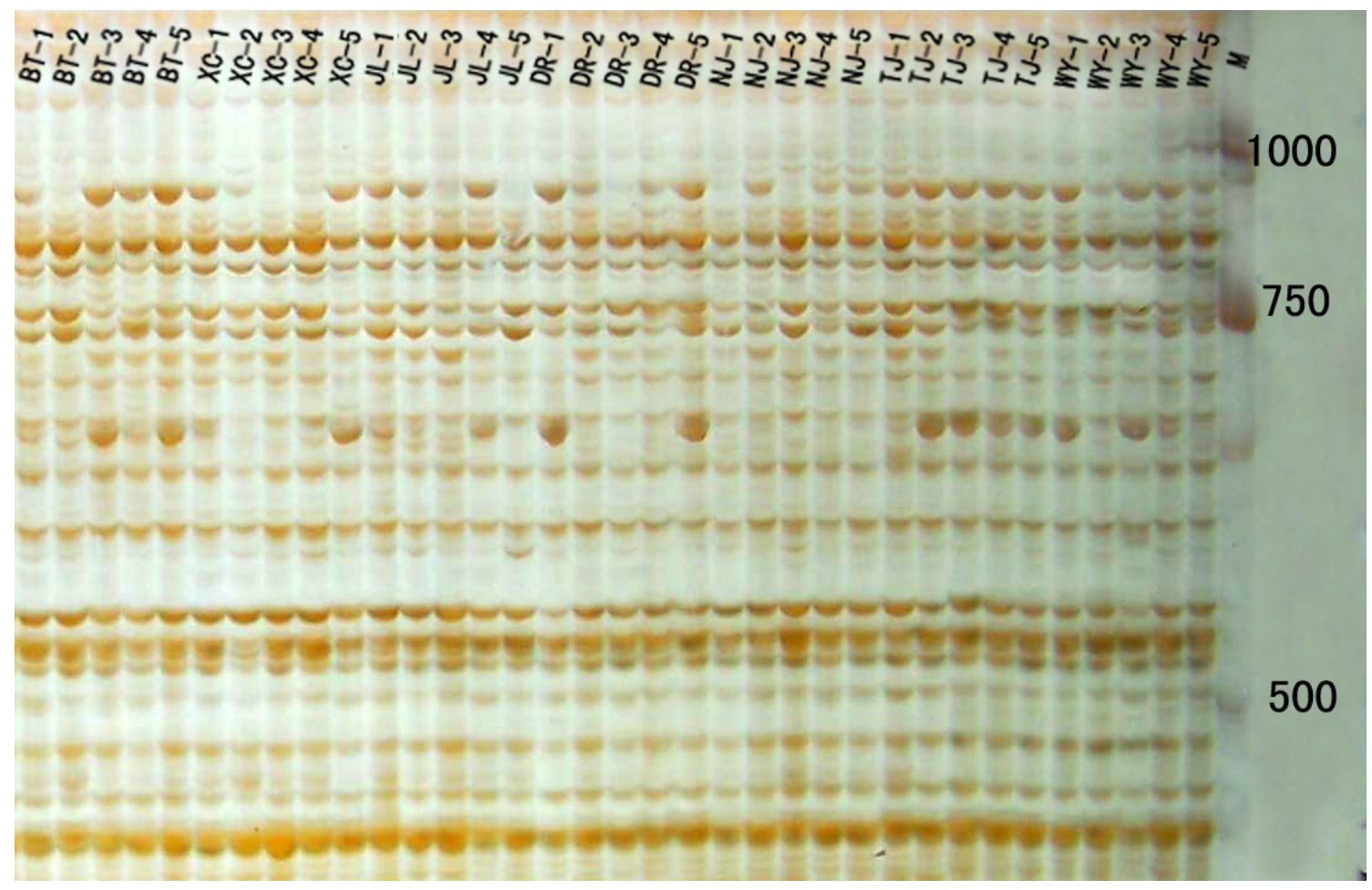

Figure 2. AFLP fingerprint of 35 walnuts genotypes using primer comparison of E-AAG/M-CCC.

The comparison of RAPD and AFLP methods revealed intensity differences in level of polymorphism rate and measuring efficiency (Table 2). And two independent species genetic similarity matrices were produced for the RAPD and AFLP data to calculate genetic distance. The RAPD GD of Western Sichuan plateau and Qinba mountainous regions is 0.289 and 0.175 , respectively. And for the AFLP, it is 0.266 and 0.206 , respectively. The $G D$ of all walnut samples are similar (Table 2). 
Table 2. Comparison of bands generated by RAPD and AFLP markers among 35 walnuts

\begin{tabular}{lcc}
\hline Parameter & RAPD maker & AFLP maker \\
\hline Number of assay units & 32 & 28 \\
Number of polymorphic bands & 279 & 1233 \\
Number of loci & 324 & 2155 \\
Polymorphic rate & $86.1 \%$ & $57.2 \%$ \\
Genetic Distance $(G D)$ & 0.273 & 0.271 \\
\hline
\end{tabular}

\subsection{Cluster Analysis}

A dendrogram was established for the 35 walnuts genotypes with UPGMA cluster analysis based on the GDs from either RAPD data or AFLP data presented in Figure 3 and Figure 4. Both have a high co-phenetic coefficient and therefore show a good fit with $G D$ values.

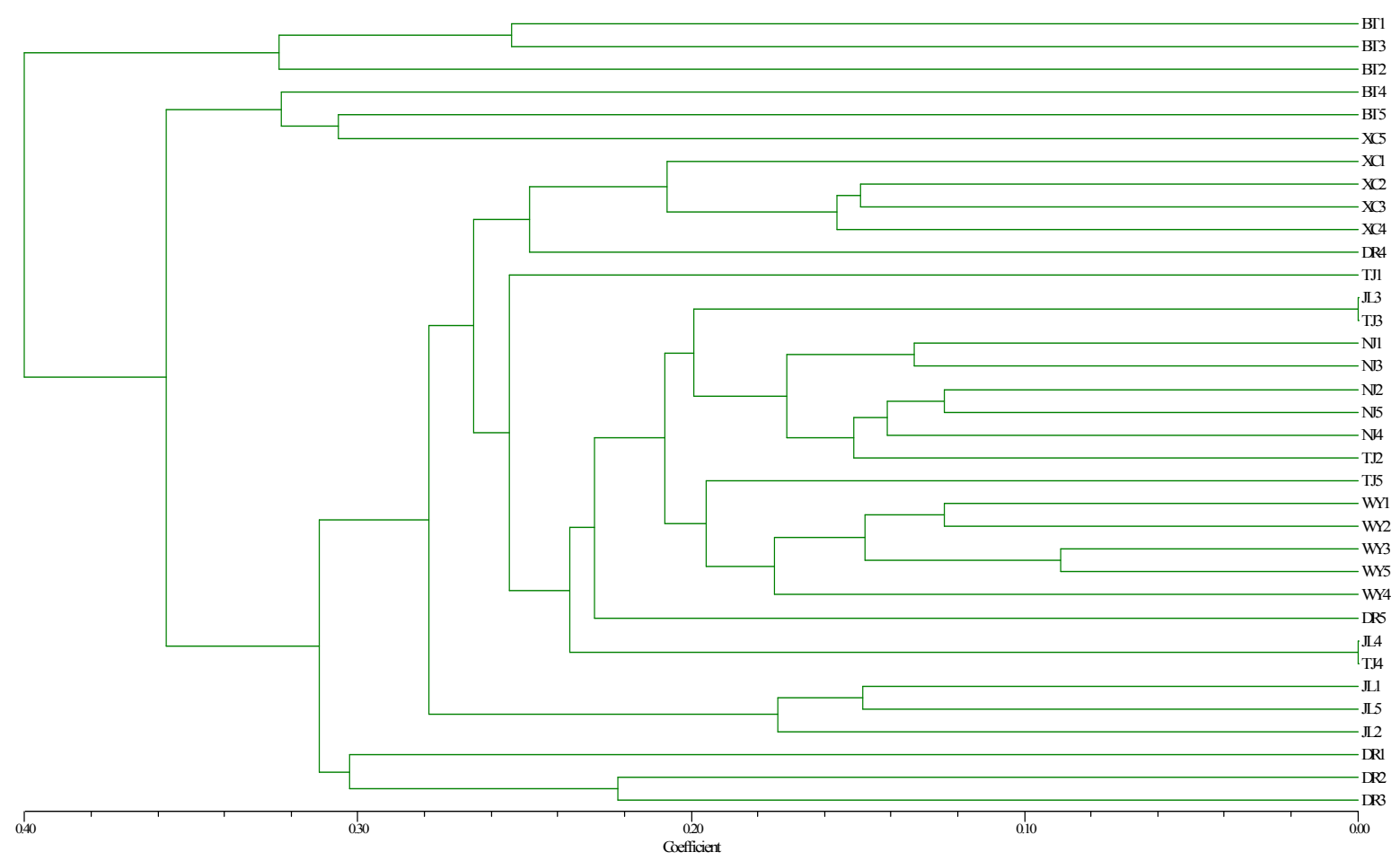

Figure 3. Dendrogram of the 35 walnut cultivars included in this study generated by un-weighted pair group method analysis (UPGMA) cluster analysis from the similarity matrix obtained using RAPD genetic distance

Clustering based on RAPD data divided the 35 walnuts genotypes into three clusters at $G D=0.34$ level (Figure 3 ), designated III. Cluster I included three genotypes: BT-1, BT-3, BT-2; cluster II was composed of three genotypes: BT-4, BT-5, XC-5; and of the others were grouped in cluster III.

The dendrogram derived from AFLP data also clustered samples into four groups using 28 combination primers, which was in agreement with the results based on RAPDs except for minor difference (Figure 4). Figure 3 and Figure 4 reveals the relationships among the 35 genotypes of walnuts. The lowest $G D(0.06$ or 0.09$)$ was found in the different genotype, such as 0.06 (TJ-3 VS JL-3) based on RAPDs and 0.09 (JL-1 VS JL-2) based on AFLPs. The greatest $G D$, also in the different genotype, 0.53 (BT-2 VS XC-5) based on RAPDs and 0.53 (BT-3 VS DR-2) based on AFLPs. It is possible that the different between clusters was resulted from different molecular markers. The cophenetic correlation analysis on cluster results from AFLP or RAPD data indicated the correlation of co-phenotype was remarkable $(P<0.001)$, the $R c s$ of AFLP was higher than that RAPD indicating the results of AFLP were more reliable than that of RAPD. Results revealed there was abundant genetic variance among walnuts varieties in China. 


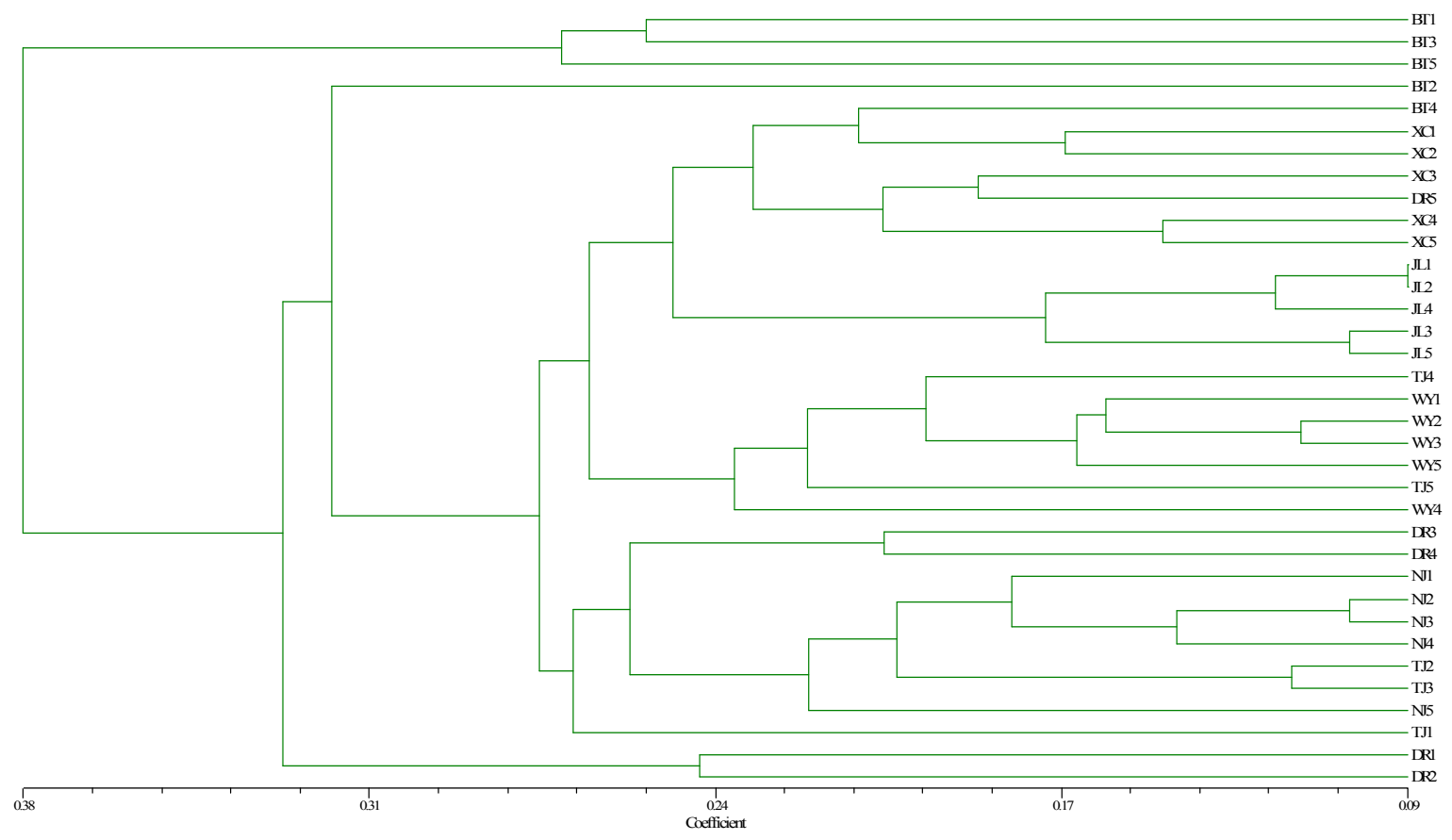

Figure 4. Dendrogram of the 35 walnut cultivars included in this study generated by un-weighted pair group method analysis (UPGMA) cluster analysis from the similarity matrix obtained using AFLP genetic distance

\section{Discussion and Conclusion}

Although there are abundant walnut germplasm resources in China, very little progress has been made in the AFLP research, especially on the genetic background information. There is no comparative study on RAPD and AFLP for walnut at the same times, only several papers on RAPD or AFLP analysis documented up to now (Cervera et al., 2000; Wu et al., 2000b; Niu et al., 2007). In the study, in comparison with AFPL markers, RAPD markers detected higher genetic loci per primer and level of polymorphism. However, AFLP revealed more polymorphic bands in a single lane than that in RAPD. Moreover, false positive products can were easily recognizable in AFLP, and subsequence gel had high resolution, making a more precise identification of similar and dissimilar AFLP allele. This indicated that AFLP marker provided a more detailed coverage throughout the genome than RAPD for walnut.

In this study, the researchers detected the genetic divergence among 35 varieties of walnuts in West of China by RAPD and AFLP markers. The degree of polymorphism (86.1\%) revealed by RAPD was higher than previous studies on walnuts (Wu et al., 2000a). The percentage of polymorphic AFLP fragments in the study $(57.2 \%)$ was also higher than the results reported by Kafkas et al (2005). Wu et al (2000b) studied that genotypes from different cluster are genetically more dissimilar than those originating from the same clusters and it is same to this study, which indicated the genetic diversities of two different regions were not in agreement with the climate. The walnuts in Qinba mountainous regions, there are similar climate and frequent genetic communication. But the walnuts in Plateau of western Sichuan plateau was opposition, geographic separation, inconvenience in traffic, lack of genetic communication, and the local diversity resources were preserved. The polymorphism of walnuts in Qinba mountainous regions was lower than that of walnuts in Western Sichuan Plateau.

\section{References}

Cervera, M. T., Remington, D., Frigerio, J. M., Storme, V., Ivens, B., Boerjan, W., \& Plomion, C. (2000). Improved AFLP analysis of tree species. Canadian Journal of Forest Research, 30(10), 1608-1616. http://dx.doi.org/10.1139/x00-085

Chen, J., \& Wang, W. J. (2004). Extraction of DNA for AFLP Amplification Reaction in Teuder Walnut Leaves. Journal of Agricultural University of Hebei, 6(27), 44-47 (in Chinese with English Abstract). http://hbnydxxb.periodicals.net.cn/default.html

Di, H., Chen, Y. L., \& Jin, L. P. (2006). Genetic diversity analysis of Chinese main potato cultivars by RAPD 
and AFLP markers. Acta Agronomica Sinica, 32(6), 899-904 (in Chinese with English Abstract). http://www.cqvip.com/qk/90181x/200606/21997415.html

Fornari, B., Malvolti, M. E., Taurchini, D., Fineschi, S., Beritognolo, I., Maccaglia, E., \& Cannata, F. (2001). Isozyme and organellar DNA analysis of genetic diversity in natural/naturalised European and Asiatic walnut (Juglans regia L.) populations. Acta Horticulturae, 544, 167-178. http://www.actahort.org/books/544/544_23.htm

Jia, H. S., \& Xu, Y. N. (2006). Walnut staminate flowers can be explored as a supplementary plant oil source. Journal of Integrative Plant Biology, 48(4), 377-380. http://dx.doi.org/10.1111/j.1744-7909.2006.00191.x

Kafkas, S., Ozkan, H., \& Sutyemez, M. (2005). DNA polymorphism and assessment of genetic relationships in walnut genotypes based on AFLP and SAMPL markers. Journal of the American Society for Horticultural Science, 130(4), 585-590. http://journal.ashspublications.org/content/130/4/585.short

Li, G. T., Ai, C. X., Zhang, L. S., Wei, H. R., \& Liu, Q. Z. (2011). ISSR Analysis of Genetic Diversity among Seedling Walnut (Juglans spp.) Populations. Journal of Plant Genetic Resources, 12(4), 640-645. (in Chinese with English Abstract). http://d.wanfangdata.com.cn/Periodical_zwyczyxb201104026.aspx

Lu, G. Y., Yang, G. S., \& Fu, T. D. (2001). Silver-stained AFLP- a novel assay for DNA fingerprinting in Brassica napus. Journal of Huazhong Agricultural University, 20(5), 413-415. (in Chinese with English Abstract). http://d.wanfangdata.com.cn/Periodical_hznydx200105002.aspx

Malvolti, M. E., Fornari, B., Maccaglia, E., \& Cannata, F. (2001). Genetic linkage mapping in an intraspecific cross of walnut (Juglans regia L.) using molecular markers. Acta Horticulturae, 544, 179-185. http://www.actahort.org/books/544/544_24.htm

Martínez, M. L., Labuckas, D. O., Lamarque, A. L., \& Maestri, D. M. (2010). Walnut (Juglans regia L.): genetic resources, chemistry, by-products. Journal of the Science of Food and Agriculture, 90(12), 1959-1967. http://dx.doi.org/10.1002/jsfa.4059

Niu, J. X., Wang, L., Dai, Y. X., Li, R., Yang, X. K., \& Lv, J. Q. (2007). Identification of AFLP Makers Linked to Early-Bearing Gene in Walnut. Molecular Plant Breeding, 5(2), 266-268. http://d.wanfangdata.com.cn/periodical_fzzwyz200702062.aspx

Qi, J. X., Hao, Y. B., Zhu, Y., Wu, C. L., Wang, W. X., \& Leng, P. (2011). Studies on Germplasm of Juglans by EST-SSR Markers. Acta Horticulturae Sinica, 38(3), 441-448. (in Chinese with English Abstract). http://d.wanfangdata.com.cn/periodical_yyxb201103005.aspx

Soriano, J. M., Romero, C., Vilanova, S., Llácer, G., \& Badenes, M. L. (2005). Genetic diversity of loquat germplasm (Eriobotrya japonica (Thunb) Lindl) assessed by SSR markers. Genome, 48(1), 108-114. http://dx.doi.org/10.1139/g04-101

Vos, P., Hogers, R., Bleeker, M., Reijans, M., van de Lee, T., Hornes, M., Friters, A., Pot, J., Paleman, J., Kuiper, M., \& Zabeau, M. (1995). AFLP: a new technique for DNA fingerprinting. Nucleic Acids Research, 23(21), 4407-4414. http://dx.doi.org/doi: 10.1093/nar/23.21.4407

Wu, Y. M., Liu, Y., Dong, F. X., \& Xi, S. K. (2000a). Study on different ecological types of Chinese walnut using RAPD markers. Journal of Beijing Forestry University, 22(5), 23-27. (in Chinese with English Abstract). http://www.cqvip.com/qk/95250x/200005/4625787.html

Wu, Y. M., Pei, D., Xi, S. K., \& Li, J. R. (2000b). A study on the genetic relationship among species in Juglans L. Using RAPD Makers. Acta Horticulturae Sinica, 27(1), 17-22. (in Chinese with English Abstract). http://www.cqvip.com/qk/90024x/200001/4188492.html

Yang, L. X. (2005). Effect of water extracts of larch on growth of Manchurian walnut seedings. Journal of Forestry Research, 16(4), 285-288. http://dx.doi.org/10.1007/BF02858190

Zhang, H. P., Niu, J. X., Ma, B. G., Hu, H. F., \& Wang, G. A. (2003). Method of DNA Extraction and RAPD Reaction System in Walnut. Journal of Shihezi University (Natural Science), 4(7), 267-270 (in Chinese with English Abstract). http://d.wanfangdata.com.cn/Periodical_shzdxxb200304003.aspx

Zhao, H., Bughrara, S. S., \& Oliveira, J. A. (2006). Genetic diversity in colonial bentgrass (Agrostis capillaris L.) revealed by EcoRI-MseI and PstI-Mse. Genome, 49(4), 328-335. http://dx.doi.org/10.1139/g05-113 